Instructions for authors, subscriptions and further details:

\title{
http://mcs.hipatiapress.com
}

\section{Hegemonic Masculinities and Camouflaged Politics: Unmasking the Bush Dynasty and its War against Iraq}

Ana Burgués ${ }^{1}$

1) Universitat de Barcelona, Spain

Date of publication: February $21^{\text {th }}, 2016$

Edition period: February 2016-June 2016

To cite this article: Burgués, A. (2016). Hegemonic Masculinities and Camouflaged Politics: Unmasking the Bush Dynasty and its War against Iraq [Review of the book]. Masculinities and Social Change 5(1), 95-96-. doi: 10.17583/MCS.2016.1951

To link this article: http://dx.doi.org/10.4471/MCS.2016.1951

\section{PLEASE SCROLL DOWN FOR ARTICLE}

The terms and conditions of use are related to the Open Journal System and to Creative Commons Attribution License (CC-BY). 
MCS - Masculinities and Social Change Vol. 5 No. 1 February 2016

pp. 95-96

\section{Reviews (II)}

Messerschmidt, J. W. (2015). Hegemonic Masculinities and Camouflaged Politics: Unmasking the Bush Dynasty and its War against Iraq. New York: Routledge. ISBN: 978-1-59451-817-1

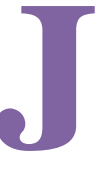

ames W. Messerschmidt es un reputado investigador en el campo de las masculinidades en cuya trayectoria académica sobresale un artículo publicado en el año 2005 en la revista Gender and Society sobre la redefinición del concepto de Masculinidad Hegemónica elaborado por Raewyn Connell. Esta publicación significó poner nuevos cimientos a la idea de masculinidad dominante que Connell había lanzado en los años 80. En esta línea també se sitúa el libro Hegemonic Masculinities and camouflaged politics publicado en el año 2015 y que tiene como principal propósito desgranar las figuras de George Bush Senior y George Bush Junior y su relación con la definición de masculinidad hegemónica. Para ello el autor divide el libro en tres partes diferenciadas. En la primera parte el autor hace una revisión teórica profunda en la que se hace un análisis crítico al concepto de masculinidad hegemónica. En las siguientes partes Messerschmidt lleva a cabo un análisis del discurso de las declaraciones de Bush Senior y Bush Junior y los efectos que ello ha tenido en la historia de Estados Unidos de América.

Algunas ideas que se nos introduce en el libro nos enseñan datos poco conocidos de la historia de la saga de los Bush. Por ejemplo, se nos explica la incredulidad de Bush padre ante el hecho que su hijo menor pudiera convertirse en el estandarte masculino de su estirpe. Messerschmidt también introduce la encrucijada que significa para los Bush definir su identidad de género en un momento social e histórico en los que los cimientos del patriarcado se están cuestionando con la llegada del feminismo, la teoría

2016 Hipatia Press

ISSN: 2014-3605

DOI: 10.17583/MCS.2016.1951 
queer, los movimientos LGBTI, etc. De todas formas, y a pesar de este contexto específico, se ponen de manifiesto en el libro como ambos Bush, y con especial hincapié Bush Junior, han contribuido a difundir y desarrollar una masculinidad hegemónica a nivel global a partir de sus liderazgos en la Guerra de Iraq y en la Guerra contra el terrorismo islámico.

Como se ha mencionado anteriormente, la guerra de Iraq del año 91 y la guerra contra el terror, iniciada por Bush hijo después de los ataques de AlQaeda, son utilizados por el autor del libro como pretextos para analizar como las actuaciones y discursos de ambos presidentes de los Estados Unidos reforzaron la masculinidad hegemónica en occidente. En el caso de Bush padre se explica una de las principales operaciones militares que se llevaron a cabo durante la Guerra del Golfo: Operation Desert Storm que significaron más de 100 horas de crueles intervenciones militares. Por otro lado, se recogen también algunas declaraciones de Bush hijo donde se pone de manifiesto su afán de poder a toda y costa y su visión de Iraq como un territorio propenso para conseguir dicho objetivo: Iraq remains relatively unexplored, offering big companies a potentially easy-to-tap source of growth (p.143). 